\title{
A Demographic Presentation of the Relationship between Parents' Profession and Children's Education in Remote Small Islands in the Aegean Sea: A Developmental Approach
}

\author{
Efrosini Pafili ${ }^{1} \&$ John Mylonakis ${ }^{2}$ \\ ${ }^{1}$ University of Piraeus, Episkopio, Syros, Greece \\ ${ }^{2}$ Glyfada, Athens, Greece \\ Correspondence: Efrosini Pafili, University of Piraeus, Episkopio, Syros 84100, Greece. E-mail: \\ efipaf@hotmail.com
}

Received: April 17, 2012 Accepted: May 10, 2012 Online Published: May 30, 2012

doi: $10.5539 /$ jsd.v5n6p 113

URL: http://dx.doi.org/10.5539/jsd.v5n6p113

\begin{abstract}
The prospects of raising the level of the economic development of the society depend to a large extent, both on the quantitative evolution of the economically active population of the society and on the level of the education. The scope of this article is to examine the relationship between the parents' profession and the educational level and occupational choice of the children in remote areas. The survey was based on a structured questionnaire distributed to a sample of 800 adolescents and their parents in the Cyclades prefecture in the Aegean Sea. Research results showed that students do not show statistically significant difference in their performance in both theoretical and in positive direction lessons, regardless of age of their parents. Also, their parents' age does not affect teenagers' in foreign languages, their participation in cultural and sporting activities, as well as, in reading extracurricular books. On the contrary, it does affect the student's training in new technologies.
\end{abstract}

Keywords: education, economic development, family status, profession, technologies, income, occupation, culture

\section{JEL Classification Code: I2}

\section{Introduction}

It is generally accepted that in order to ensure the economic development of a country, capital and natural resources are not enough factors. It requires more a well-trained workforce that can deliver enough production. For this reason, the need of particular educational facilities to properly train the human resources is deemed as the major development factor.

The prospects of raising the level of the economic development of the society depend to a large extent, both on the quantitative evolution of the economically active population of the society and on the expected evolution of the level of the education (Chatzidima, 2002). Education makes a person more productive and leads to an increase in personal income (Schultz, 1968; Psacharopoulos, 1999). In choosing the level of education, the key role is played by the family, because this is the central forum through which the individual has his first contact with the social environment. The individual, through the family, derives his first impulses, aspirations, ambitions and grows as a personality. According to studies by economists and sociologists, the role of the family is summarized in key categories, including reproduction, economic, educational, and psychological. These will affect the individual, sometimes directly and sometimes indirectly in his professional choices (Psacharopoulos $\&$ Kazamias, 1985).

The scope of this paper is to examine the relationship between parents' profession and their children's educational level and occupational choice living in remote areas (away from urban centers). This is a social issue that should concern all those involved in the economic development and education in all countries of the world.

\section{Research Methodology}

For the scope of this study, a demographic survey was carried out in 31 small and isolated islands of Cyclades in the Aegean Sea. The survey was based on a structure questionnaire which was distributed to a sample of 800 adolescents in the Cyclades prefecture. Then, it was asked by their parents to complete the questionnaire. 
The sampling technique which was applied was the stratified sampling. According to this technique, the sample been allocated according to population characteristics in layers and then within each layer, students were selected randomly. This was used because it is a statistical analysis technique with optimal mathematical properties that ensure the successful distribution of the sample in both the layers and within them.

Table 1. Distribution of sample by island

\begin{tabular}{cccc}
\hline Municipality/community & $\begin{array}{c}\text { Total sample } \\
\text { municipality }\end{array}$ & $\begin{array}{c}\text { Greek sample } \\
\text { municipality }\end{array}$ & $\begin{array}{c}\text { Foreigners sample } \\
\text { municipality }\end{array}$ \\
\hline Amorgos & 13 & 12 & 1 \\
Andros & 29 & 23 & 6 \\
Ano Syros & 24 & 22 & 2 \\
Drimalias & 43 & 43 & 0 \\
Exombourgo & 19 & 19 & 0 \\
Ermoupolis & 94 & 92 & 3 \\
Thyra & 88 & 72 & 16 \\
Ios & 13 & 12 & 1 \\
Kea & 17 & 15 & 2 \\
Korthi & 18 & 18 & 0 \\
Kythnos & 18 & 18 & 0 \\
Milos & 34 & 32 & 2 \\
Mykonos & 66 & 53 & 13 \\
Naxos & 85 & 79 & 6 \\
Paros & 91 & 85 & 6 \\
Posidonia & 21 & 21 & 0 \\
Serifos & 10 & 10 & 0 \\
Sifnos & 17 & 16 & 1 \\
Tinos & 37 & 33 & 4 \\
Ydrousa & 24 & 23 & 0 \\
Anafi & 2 & 2 & 0 \\
Antiparos & 7 & 6 & 1 \\
Donousa & 1 & 1 & 0 \\
Iraklia & 1 & 1 & 0 \\
Kimolos & 5 & 5 & 0 \\
Koufonisia & 3 & 2 & 0 \\
Ia & 9 & 4 & 0 \\
Panormos & 5 & 1 & 0 \\
Sikinos & 2 & 434 & 0 \\
Sxinousa & 1 & & 0 \\
Folegandros & 500 & 1 & 0 \\
Total & & 1 & 0 \\
\hline
\end{tabular}

Source: Perfection of South Aegean.

The present study was based on a population sample of 800 students from 31 isolated islands of the Cyclades Prefecture (Table 1). Some population characteristics such as the gender were used to make suitable pilot survey. This pilot study was used to obtain data from the population which resulted in the efficient implementation of the selected sampling technique. The collection of representative answers was found statistically accepted to draw conclusions for the population with the greatest precision. 


\section{Research Results}

\subsection{Teenagers' Characteristics in Relation to Education}

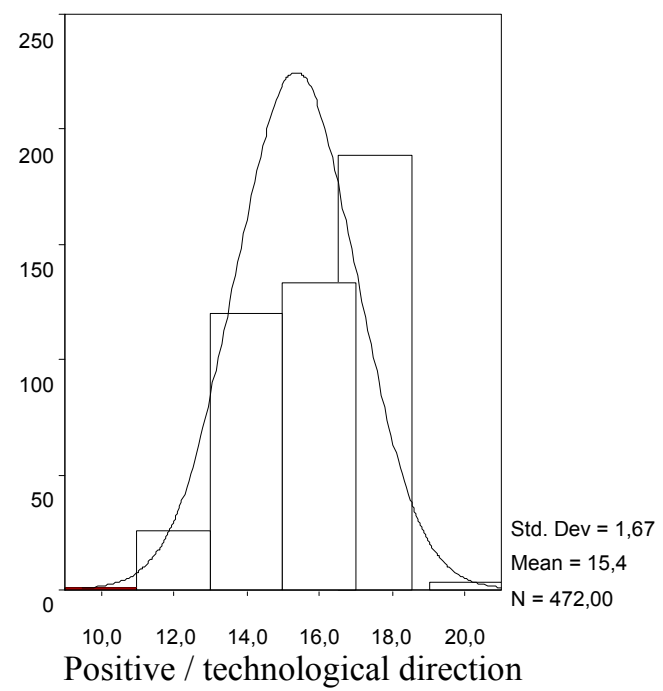

Figure 1. Distribution of the Sample on the average performance in positive/technological direction lessons

The first feature that was studied is the teenager's performance (on selected lessons) through which the slope of the teenager emerges. For the purposes of this study two scales were used to measure the average performance of the teenager in theoretical and in positive direction lessons. It was found that teenagers have minor differences in their in the theoretical (Ancient and Modern Greek, History, Latin) and in positive direction (Mathematics, Physics, Chemistry, Biology) lessons (Figures 1 \& 2).

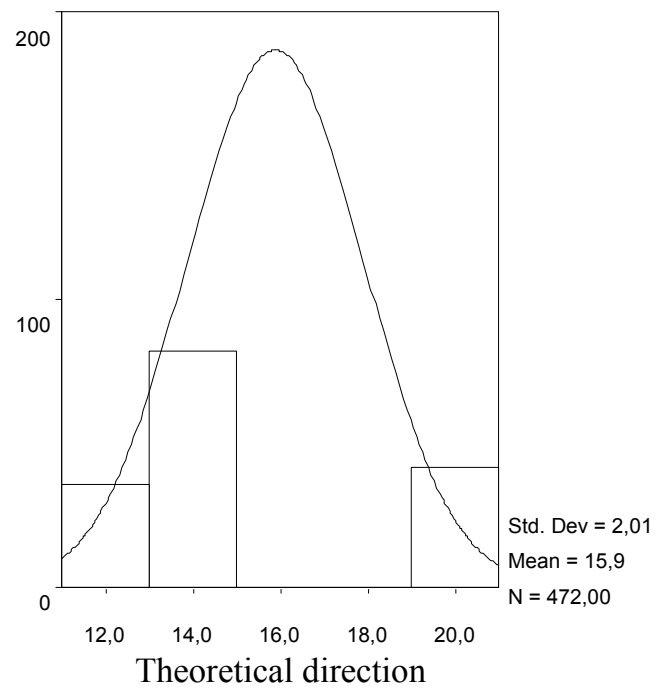

Figure 2. Distribution of the Sample on the average performance in theoretical direction lessons

\subsubsection{Teenagers' Performance in Extracurricular Activities}

A second characteristic found is that teenagers study foreign languages ( $98.7 \%$ of teenagers) and occupy with new technologies $(88.6 \%$ of teenagers). Participation in cultural activities $(25.6 \%$ involved) and sports events (38.8\% involved) are two other teenagers' characteristics found, as well as, the reading of extracurricular books and / or newspapers ( $92.4 \%$ of teenagers). 


\subsubsection{Teenagers' Characteristics Connected to the Standard of Living}

Relative to the level of teenagers' life is the distribution of the attribute "average daily spending" (Figure 3). As shown, the average daily cost is about 2 Euros with a standard deviation approximately equal to 1 Euro (Figure 3). Another interesting feature associated with the standard of living is the "favorite daily activity".

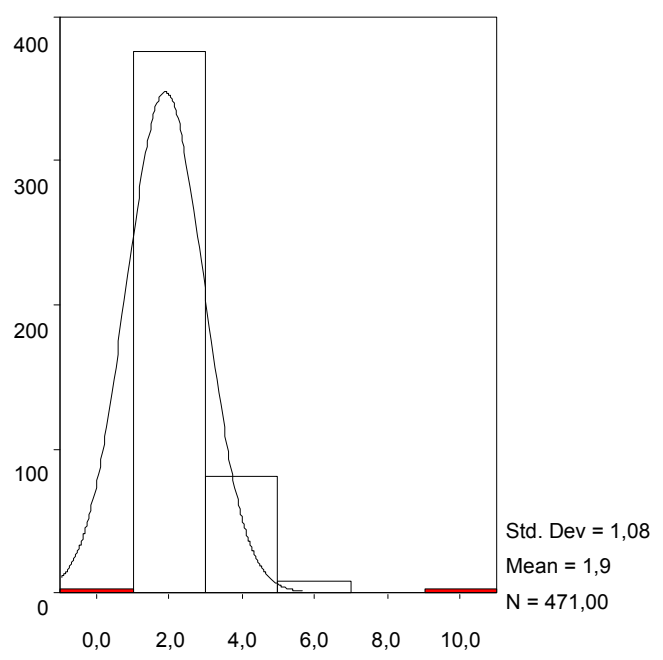

Sample to the average daily cost

Figure 3. The distribution of the sample to the average daily cost

3.1.3 Relationship between the Demographic Characteristics of the Parents and Teachers and the Characteristics of the Teenagers

For the purposes of this study, two scales are used to measure the average teenagers' performance in theoretical and positive direction lessons.

\subsection{Study of the Effect of the Variable "Age of Father"}

\subsubsection{Teenagers' Performance on Their Lessons}

As a first step in this study we want to see if the father's age affects the performance of the teenager on his lessons. From the study of these two measurement scales (implemented control One-Way ANOVA, teenagers do not differ in their performance both in theoretical subjects (P-Value 0,927$)$ and in subjects of positive direction (P-Value 0,422).

Figures 4 and 5 present graphically the distributions of the two scales measuring the average performance which characterize the teenager in theoretical and in positive direction lessons, respectively. 


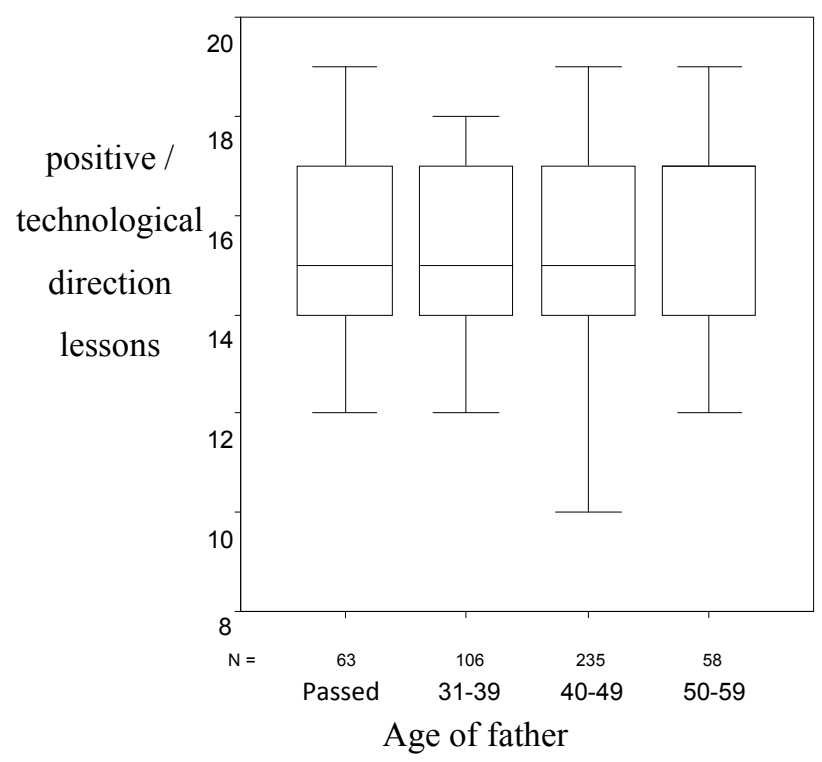

Figure 4. Distribution of the Sample on the average performance in positive/technological direction lessons

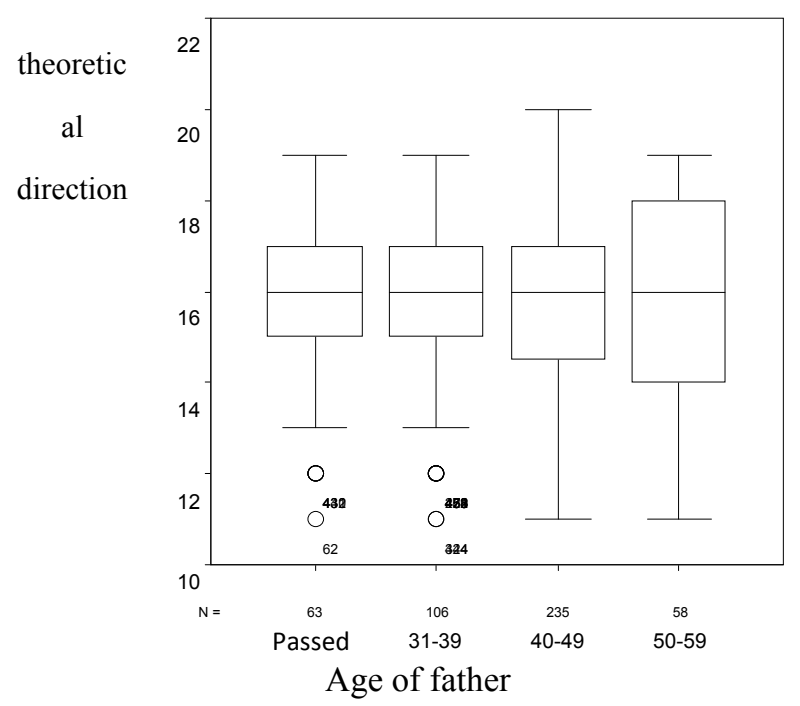

Figure 5. Distribution of the Sample on the average performance in the courses of theoretical direction

\subsubsection{Teenagers' Performance on Foreign Languages Learning and the Use of New Technologies}

A second characteristic is the study of foreign languages ( $98.7 \%$ of the teenagers are studying) and a third one is the study on new technologies ( $88.6 \%$ of the teenagers are studying). As shown in Table 2, there is no statistically significant difference in language studies.

Table 2. Age of father (P-Value: 0.517)

\begin{tabular}{cccccc}
\hline Foreign & \multicolumn{4}{c}{ Age of father } & Total \\
\cline { 2 - 4 } Languages & Extinct & $31-39$ & $40-49$ & $50-59$ & \\
Yes & 62 & 106 & 232 & 58 & 458 \\
No & 1 & 0 & 3 & 0 & 4 \\
Total & 63 & 106 & 235 & 58 & 462 \\
\hline
\end{tabular}


On the contrary, it was found a statistically significant difference on study of new technologies (Table 3). More specifically, Chi-square test gave a P-Value equal to 0.044 , which means that the hypothesis of the independence of two characteristics was dismissed.

Table 3. Monitoring variations of the teenager's training on new technology-based on the age of the father (P-Value: 0.044)

\begin{tabular}{cccccc}
\hline New & \multicolumn{4}{c}{ Age of the Father } & Total \\
\cline { 2 - 5 } Technology & Extinct & $31-39$ & $40-49$ & $50-59$ & \\
Yes & 51 & 100 & 204 & 53 & 408 \\
No & 12 & 6 & 31 & 5 & 54 \\
Total & 63 & 106 & 235 & 58 & 462 \\
\hline
\end{tabular}

\subsubsection{The Participation of the Teenagers in Various Activities}

Participation in cultural activities (25.6\% of teenagers participate) and sports (38.8\% of teenagers involved) are two other characteristics that are studied and sixth feature is the reading extracurricular books and/or newspapers (92, 4\% of the teenagers read). Chi - Square Test showed no statistically significant variations between these characteristics and the age of the father (Table 4).

Table 4. Monitoring variations of the average performance of the teenager in positive and theoretical direction lessons based on the nationality of teenagers

\begin{tabular}{cccccc}
\hline & $\begin{array}{c}\text { Social class based on } \\
\text { occupation }\end{array}$ & SAMPLE & AVERAGE & $\begin{array}{c}\text { STANDARD } \\
\text { DEVIATION }\end{array}$ & P-VALUE \\
\hline \multirow{3}{*}{ positive direction } & 1,00 & 115 & 15,8522 & 1,72822 \\
& 2,00 & 114 & 15,3070 & 1,52923 & 0,002 \\
& 3,00 & 167 & 15,1138 & 1,68415 &, 00000 \\
theoretical & 4,00 & 2 & 15,0000 & 1,95260 \\
direction & 1,00 & 115 & 16,4696 & 1,97879 & 0,003 \\
& 2,00 & 114 & 15,5175 & 1,98390 & 3,53553 \\
\hline
\end{tabular}

\subsection{Study of the Effect of the Variable Teenagers' "Father's Occupation"}

\subsubsection{Teenagers' Performance on Their Lessons}

As a next step of this study, we aimed to see if the profession of the father affects the performance of the teenager on his lessons. The factor of the father's occupation can be characterized as an indicator of the social class (Figures $6 \& 7$ ). From the study of these two measurement scales (implemented control One-Way ANOVA), teenagers differ in their performance both in theoretical lessons (P-Value 0,002) and in lessons of positive direction (P-Value 0,003, Table 4). Figures 6 and 7 present graphically the distributions of the two scales measuring the average performance. 


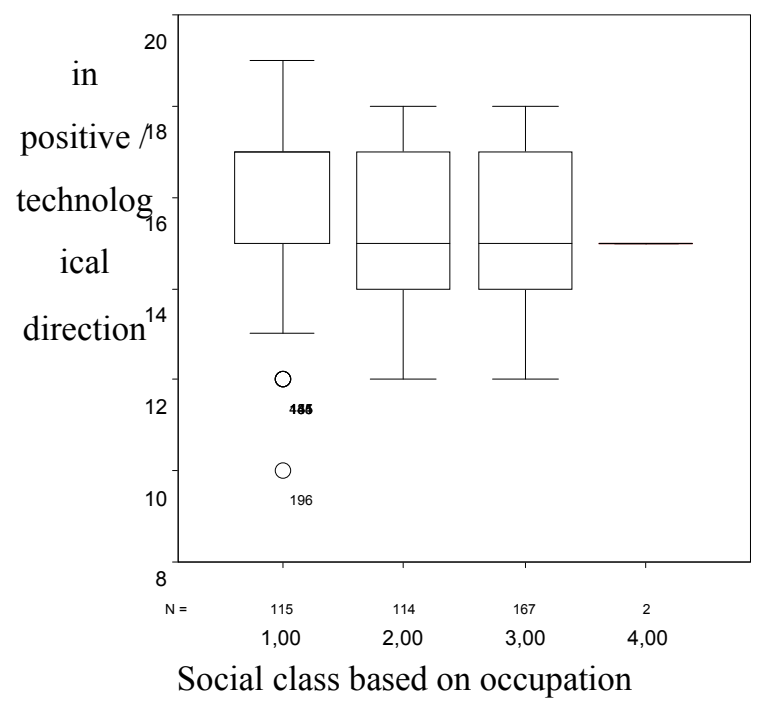

Figure 6. Distribution of the Sample on the average performance in positive/technological direction lessons

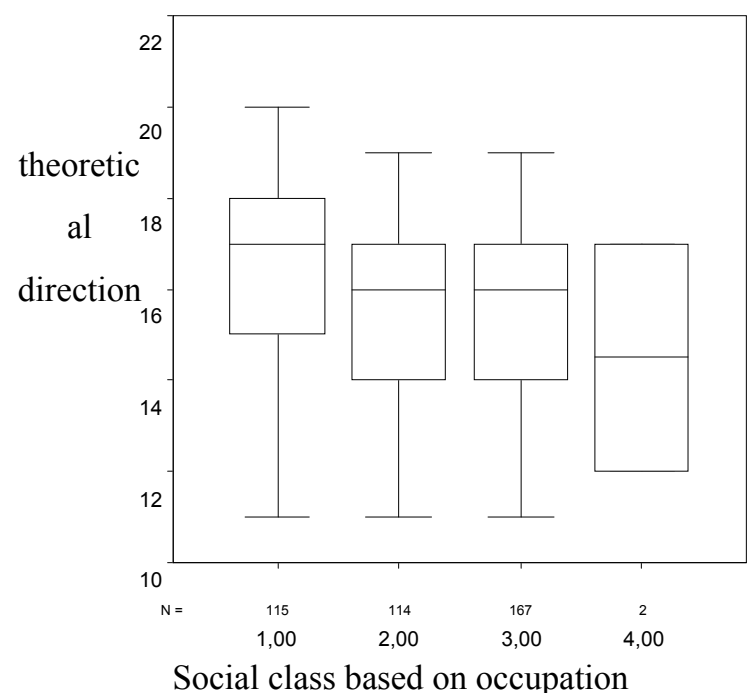

Figure 7. Distribution of the Sample on the average performance in the courses of theoretical direction

An interesting feature is that while the occupation of the father has an impact on the teenagers' performance, the average monthly income of the father has no effect upon the teenagers' performance. From the study of these two measurement scales (One-Way ANOVA), it was found that teenagers do not differ in their performance both in theoretical lessons (P-Value 0,068 ) and in lessons of positive direction (P-Value 0,500).

\subsubsection{Teenagers' Performance on Studding Foreign Languages and Using New Technologies}

Regarding the relationship between the study of foreign languages and using new technologies and the fathers' profession, it was found no statistically significant difference in language studies (P-Value 0,0487) when in fact there is a statistically significant difference in studies on using new technologies (P-Value 0,049).

\subsubsection{Teenagers' Participation in Sports and Cultural Activities}

Regarding the relationship between participation in sports and cultural activities and the fathers' profession, it was found that there is no statistically significant difference in participation in sports activities (P-Value 0,0673), when in fact there is a statistically significant difference in participation in cultural activities (P-Value 0,0446 ). 


\subsection{Study of the Effect of the Variable "Income of the Father"}

\subsubsection{Teenagers' Performance on Studding Foreign Languages and Using New Technologies}

Regarding the relationship between the foreign language studies and the studies on new technologies, with the monthly income of the father, that there is no statistically significant difference in language studies (P-Value 0,935 ), while there is also no statistically significant difference in studies on new technologies (P-Value 0,161 ).

\subsubsection{Teenagers' Participation in Cultural and Sporting Activities}

Regarding the relationship between participation in cultural and sporting activities with the monthly fathers' income, it was found no statistically significant difference in participation in sports activities (P-Value 0,307). On the contrary, there is a statistically significant difference in participation in cultural activities and the monthly income of the father (P-Value 0,037).

3.4.3 Study of the Effect of the Variable "Age of the Mother", on the Characteristics of the Teenager

\subsubsection{Teenagers' Performance on Their Lessons}

In continuation of our study, we aim to see if the maternal age affects the performance of the teenager on his lessons. From the study of these two measurement scales (implemented control One-Way ANOVA), the teenagers do not differ in their performance both in theoretical lessons (P-Value 0,253 ) and in lessons positive direction (P-Value 0,658). Figures 8 and 9 present graphically the distributions of two scales measuring the average performance of the teenager in theoretical lessons and in lessons of positive direction.

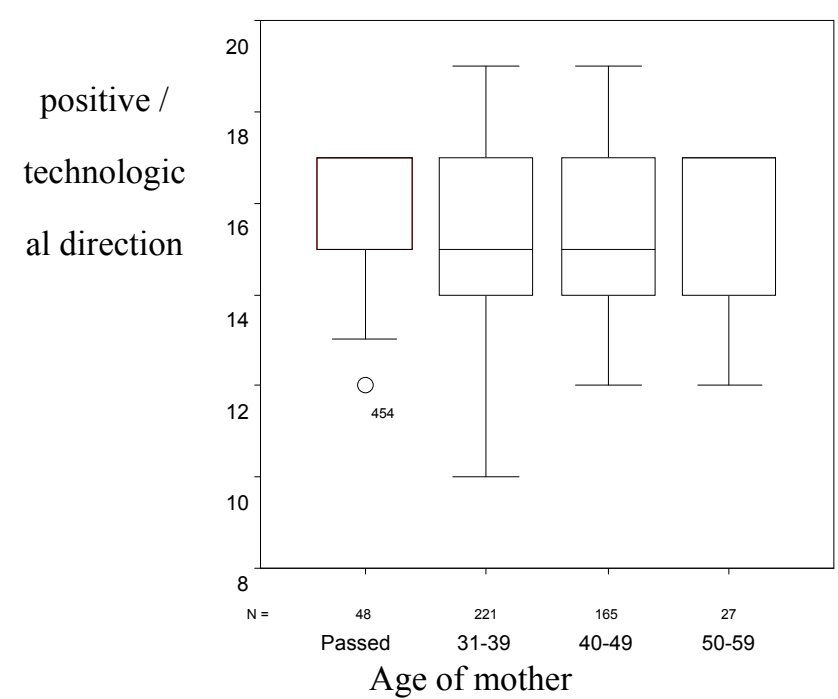

Figure 8. Distribution of the Sample on the average performance in positive/technological direction lessons 


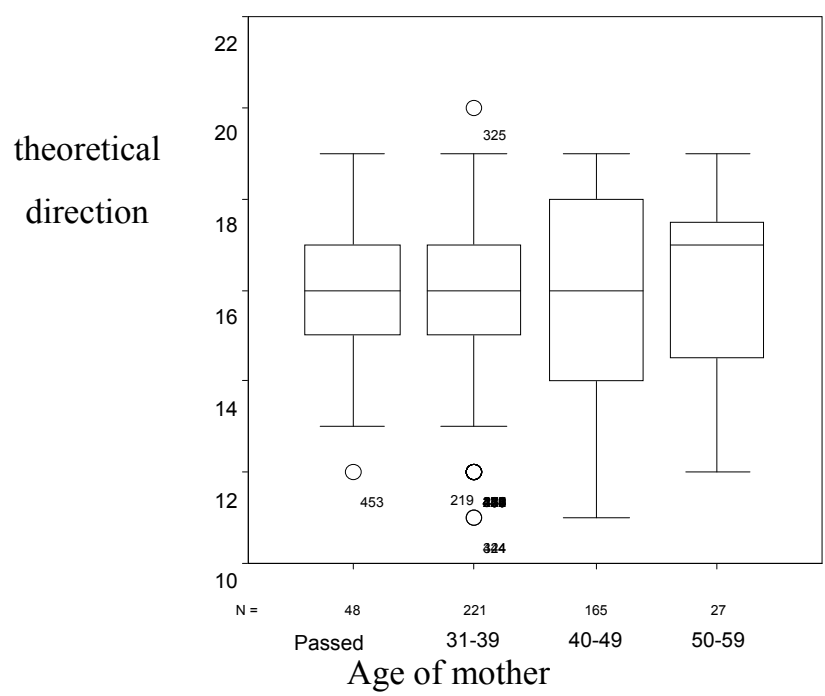

Figure 9. Distribution of the Sample on the average performance in the courses of theoretical direction

\subsubsection{Teenagers' Performance on Foreign Languages and the Use of New Technologies}

As shown in Table 5, there is a statistically significant difference in studying of foreign languages. More specifically, Chi-square test showed a P-Value equal to 0.12 from which we conclude that the hypothesis of independence of two characteristics (maternal age and teenager's "studies in foreign languages" is rejected (Table 5).

Table 5. Monitoring variations of the teenager's studies on foreign languages based on the age of the mother (P-Value: 0.012)

\begin{tabular}{cccccc}
\hline Foreign & \multicolumn{4}{c}{ Age of the mother } & \multirow{2}{*}{ Total } \\
\cline { 2 - 5 } Languages & Extinct & $31-39$ & $40-49$ & $50-59$ & \\
\hline Yes & 48 & 221 & 159 & 27 & 455 \\
No & 0 & 0 & 6 & 0 & 6 \\
Total & 48 & 221 & 165 & 27 & 461 \\
\hline
\end{tabular}

Also, it was found statistically significant difference between the studies on new technologies and the maternal age (Table 6).

Table 6. Monitoring variations of the teenager's training on new technology-based on the age of the mother (P-Value: 0.002)

\begin{tabular}{cccccc}
\hline \multirow{2}{*}{ New Technology } & \multicolumn{4}{c}{ Age of the mother } & Total \\
\cline { 2 - 5 } & Extinct & $31-39$ & $40-49$ & $50-59$ & \\
\hline Yes & 46 & 200 & 134 & 27 & 407 \\
No & 2 & 21 & 31 & & 54 \\
Total & 48 & 221 & 165 & 27 & 461 \\
\hline
\end{tabular}

\subsubsection{Results of the Control Link}

Chi-square test showed a P-Value equal to 0.02 which means that the hypothesis of independence of the two characteristics (maternal age and teenager's "studies on new technologies") is rejected (Table 6). 


\subsubsection{The Participation of the Teenager in Various Activities}

Participation in cultural activities (25.6\% of teenagers involved), sports (38.8\% of adolescents participate), as well as, extracurricular reading books and/or newspapers ( $92.4 \%$ are reading), means that a large percentage of the teenager participate in extracurricular activities.

\subsection{Study of the Effect of the Variable "Mother's Occupation"}

\subsubsection{The Performance of the Teenager on His Lessons}

It was also examined whether the mothers' profession affects the teenager's performance on their lessons. The occupation factor of teenagers' mother may be regarded as an indicator of social class.

The study of these two measurement scales (One-Way ANOVA) showed that teenagers differ in their performance both in theoretical lessons (P-Value 0,001) and in lessons of positive direction (P-Value 0,001, Table 7). An interesting feature is that while the occupation of the mother affects the teenager's performance, the average monthly income of the mother has no effect on the performance of the teenager on his lessons.

Table 7. Monitoring variations of the average performance of the teenager in positive and theoretical direction lessons based on the age of the mother

\begin{tabular}{cccccc}
\hline & $\begin{array}{c}\text { Social class based } \\
\text { on occupation }\end{array}$ & SAMPLE & AVERAGE & $\begin{array}{c}\text { STANDARD } \\
\text { DEVIATION }\end{array}$ & P-VALUE \\
\hline \multirow{5}{*}{ positive direction } & 1,00 & 73 & 15,8356 & 1,49084 & \\
& 2,00 & 149 & 15,5705 & 1,58223 & 0,001 \\
& 3,00 & 14 & 14,4286 & 1,60357 & \\
theoretical direction & 4,00 & 169 & 14,9586 & 1,78404 & \\
& 1,00 & 73 & 16,5205 & 2,11548 & \\
& 2,00 & 149 & 16,0000 & 2,03682 & \\
& 3,00 & 14 & 14,5000 & 1,91150 & \\
\hline
\end{tabular}

\subsubsection{Results of the Measurement Scales}

The study of these two measurement scales (One-Way ANOVA) proved that adolescents do not differ in their performance both in theoretical lessons (P-Value 0,896 ) and in lessons of positive direction (P-Value 0,835).

\subsubsection{Teenagers' Participation in Sports and Cultural Activities}

Regarding the relationship between participation in sports and cultural activities and the mothers' profession, it was found that there is a statistically significant difference in participation in sports activities (P-Value 0,011 ). On the contrary, there is no statistically significant difference in participation in cultural activities (P-Value $0,113)$.

\subsection{Study of the Effect of the Variable "Income of the Mother"}

\subsubsection{Teenagers' Activities}

Examining the relationship of all these features with the monthly income of the mother, it was found that there is no statistically significant difference.

\section{Conclusions}

This study examined the characteristics of a sample of 800 teenagers associated with some demographic factors, like education, personal views and desires, as well as, the demographic characteristics of their parents, confirming what Gramsi said: "every man is trained by his environment and he is simultaneously training it". This study survey showed that as far as:

a) The variable "fathers' age" is concerned, students do not show statistically significant difference in their performance in both theoretical and in positive direction lessons and it does not affect the study of foreign languages, their participation in cultural and sporting activities, as well as in reading extracurricular books. 
However, it does affect the student's training in using new technologies (the largest proportion of the teenagers who study new technologies have a father of 40 to 49 years old).

b) The variable "fathers' occupation" is concerned, which can be considered an indicator of social class. The fathers' profession is considered as giving to teenagers the "stigma" at the time of birth, until they enter in the labor market. This variable affects the professional development of individuals not only at the time and stage of their choice, but also in the future.

Similarly results were found for the case of teenagers' mother. More specifically, the variable "mothers' age" showed that students are not affected in their performance, in both theoretical and positive direction lessons, as well as, it does not affect the teenager's participation in cultural and sporting activities, as well as, in reading extracurricular books. However, it does affect teenager's studies in foreign languages (the largest proportions of the teenagers who study foreign languages have a mother of 31-39 years old) and the use of new technologies (the largest proportion of the teenagers who study new technologies have a mother of 31-39 years).

As far as the variable "mothers' occupation" is concerned, which can be considered an indicator of social class; it was found that it does affect the teenagers' performance on their studies, on using new technologies, learning foreign languages studies and their participation in sports. On the contrary, it does not affect teenagers' participation in cultural activities.

Finally, considering the "mothers' average monthly income", it was found that it does not affect the performance of teenagers' in their studies, and learning foreign languages, using new technologies and participating in sports and cultural activities.

\section{References}

Chatzidima, S. (2002). The contribution of education to the economic growth. Spoudai, 52(4), 155-165.

Psacharopoulos, G. (1999). Economics of Education (2nd ed). Athens: Papazisis.

Psacharopoulos, G., \& Kazamias, A. (1985). Education and Training in Greece: Social and Economic Study of Higher Education. Athens: National Center for Social Research.

Schultz, T. W. (1968). Investment in Human Capital. American Economic Review, 51, 1-17. 